CORRESPONDENCE

\section{Is evidence-based psychiatry a quagmire?}

Evidence-based medicine in general often feels like a quagmire. Wallace (2011) addresses the perils and pitfalls of evidence-based psychiatry in particular. Going through journals such as The Psychiatrist and the British Journal of Psychiatry, a nervous reader might become bogged down in the statistical methods. Twenty years ago, $t$-tests and ANOVA were common; today, we have SPSS computer programs and all the baffling complexities of logistic regression and factor analysis (Howitt 2008).

What articles such as Wallace's attempt is a perhaps impossible task - to make the ultracomplicated welding of mathematics and medicine comprehensible.

Statistics, as much as theology, is prone to internecine debate, with different contingents disagreeing over the concepts involved. Wallace refers to both $P$-values and confidence intervals: nowadays, the former have been replaced to a large extent by the latter (Gardner 1990). Wallace's statement that the 'number needed to treat is regarded as the most useful measure of the benefit of a treatment' is open to debate. The number needed to treat is still embedded in some controversy, and many prefer to rely on the underlying absolute risk difference.

So how much is evidence-based psychiatry like hazardous quagmire? Numbers and data per se are not enough. The psychiatrist without emotional insight and an intuition of the heart regarding each individual patient is a bad psychiatrist. Forcing psychiatry into the mould of the computer through statistical methods is not always for the best.

Howitt D, Cramer D (2008) Introduction to Statistics in Psychology (4th edn). Pearson.

Gardner MJ, Altman DG (1990) Statistics with Confidence. BMJ Books.

Wallace $J$ (2011) The practice of evidence-based psychiatry today. Advances in Psychiatric Treatment 17: 389-95.

Zekria Ibrahimi, psychiatric patient, Coombs Library, West London Mental Health Trust, Southall UB1 3EU, UK. Email: ibrahimizekria@googlemail.com

doi: 10.1192/apt.18.1.78

\section{Author's reply}

Ibrahimi is correct when he states that numbers and data, so much associated with evidence-based medicine, are not sufficient in dealing with the individual patient. Emotional insight, intuition and a caring attitude are also central.

The purpose of evidence-based medicine is not to replace clinical decision-making with numbers and data. Research evidence should be considered as one of many factors when making a clinical decision. Other elements to be utilised include intuition, clinical experience and, most important, the preferences of the patient. There are, of course, situations in which research evidence should be considered but then disregarded.

Sadly, medicine and psychiatry historically are littered with examples of interventions that were based on erroneous beliefs rather than evidence, many of which had less than optimal outcomes for the patient.

Currently, the push is on to make systematic reviews and research articles less of a quagmire. The emphasis is now on developing clear, readable summaries stressing conclusions and recommendations that are tailored to a specific target audience. Accessibility is becoming central. Evidence-influenced psychiatry is perhaps a better term to describe an approach that advocates consideration of research evidence as well as clinical experience and the patient's preferences in a decision-making process that is aimed at advancing the patient's best interests and their quality of care.

\footnotetext{
John Wallace, Clinical Psychologist and Consultant Psychiatrist DPhil Reader in Evidence-Based Healthcare, Kellogg College, 62 Banbury Road, Oxford University OX2 6PN, UK. Email: john. wallace@wadh.oxon.org

doi: 10.1192/apt.18.1.78a
}

\section{Physical health examination in Section 136 suites}

Hampson (2011) placed little emphasis on the initial physical assessment of detained patients. Peer-group feedback for on-call Section 12 doctors involved in these assessments in the West Midlands indicates a significant shift towards the senior psychiatrist in the responsibility for basic physical health assessment. One example was an individual with a fractured skull - identified by the assessing senior psychiatrist. The role of the psychiatric trainee in the assessment process remains uncertain. As Hampson states, it seems that very few patients are transported by ambulance. This misses an early opportunity for medical screening by paramedics and diversion to acute medical or surgical units where appropriate. Thus, the senior psychiatrist may well now be the first medically trained individual to screen patients for potentially serious non-psychiatric medical conditions resulting in behavioural disturbance. Sadly, it is recognised that senior psychiatrists may not be rehearsed in acute physical assessment (Garden 2005). Also, the facilities and equipment allowing appropriate examination can often be limited. 